\title{
Advances in Sustainability: Contributions and Outcomes of the 2nd World Sustainability Forum
}

\author{
Sylvie Flämig ${ }^{1}$ and Marc A. Rosen ${ }^{2, *}$ \\ 1 MDPI AG, Kandererstr. 25, CH-4057 Basel, Switzerland; E-Mail: sylvie.flaemig@gmx.de \\ 2 Faculty of Engineering and Applied Science, University of Ontario Institute of Technology, 2000 \\ Simcoe Street North, Oshawa, Ontario L1H 7K4, Canada \\ * Author to whom correspondence should be addressed; E-Mail: Marc.Rosen@uoit.ca; \\ Tel.: +1-905-721-8668; Fax: +1-905-721-3370.
}

Received: 13 March 2013 / Accepted: 13 March 2013 / Published: 19 March 2013

\section{Introduction and Background}

After a successful start in 2011, the 2nd World Sustainability Forum (WSF) was held on sciforum.net from 1-30 November 2012. More than 80 papers were presented and over 180 authors contributed to the multidisciplinary conference.

The objective of this short report is to sum up the contributions and discussions of the 2nd World Sustainability Forum. It is organized as follows. First, some general information on the Forum is given, then a summary of the contributions to the different sections, as well as providing an overview of the discussions. A final section including an outlook to the 3rd World Sustainability Forum concludes the article.

A special feature of the WSF is that it is an electronic conference allowing participants from all over the world to engage in discussions about sustainability and sustainable development without the limitations of travelling. This form of rapid and direct communication is especially useful for a sustainability conference. The 2nd WSF aimed at encouraging the presentation and critical discussion of research and applications of both theoretical as well as practical investigations concerned with a range of sustainability issues.

\section{Results and Discussion}

\subsection{Sections}

The contributions in this conference were centered around nine topical sections, representing many of the key issues of the day in sustainability: 

A. Environmental Sustainability
B. Corporate Social Responsibility
C. Social Values for a Sustainable Economy
D. Energy Efficiency and Renewable Energy Sources
E. Sustainable Urban Development
F. Sustainable Development Policy and Practice
G. Sustainable Entrepreneurship and Sustainability Innovation
H. Remote Sensing for Sustainable Management of Land and Biodiversity, Sustainable Agriculture
I. Related Topics

In Section A., Environmental Sustainability, 12 papers were submitted. Case studies from different regions such as Pakistan or Bangladesh were presented. Also broader issues, such as the management of natural lake water resources, the sustainability of industrial design products and political efforts, were addressed. Specific environmental issues, such as climate change, received particular attention. Reports on the impacts on ecosystems of ground-based energy systems were provided. Developments to environmental sustainability being made in different sectors of the economy, such as agriculture and food, were presented, as were contributions by industry and the corporate sector - the latter providing an overlap with some papers in Section B; available online: http://sciforum.net/conf/wsf2/sections/a/.

Topics discussed in Section B., Corporate Social Responsibility, were sustainable supplier selection as well as life cycle sustainability assessment, being two largely discussed topics in the corporate environment; available online: http://sciforum.net/conf/wsf2/sections/b/.

A wide range of different topics were published under Section C., Social Values for a Sustainable Economy. The discussion focused on socio-cultural issues, such as human development, heritage and cultural impacts, regarding protected areas in different parts of the world and included many case studies; available online: http://sciforum.net/conf/wsf2/sections/c/.

Section D., Energy Efficiency and Renewable Energy Sources, included 17 presentations of concrete sustainability issues such as renewable energy, heating, transportation, building and architecture. Advances in such technologies and such processes as photovoltaics, biofuels, wind turbines, district energy and energy storage, were presented. Improvements in efficiency, economics and environmental impact (especially related to emissions of carbon dioxide and other greenhouse gases) were provided; available online: $\mathrm{http}$ :/sciforum.net/conf/wsf2/sections/d/.

Architecture in the context of urban development was dealt with in Section E., Sustainable Urban Development. Other important topics were the sustainable development of cities, including issues like vertical growth and circular systems, polyfunctional zoning, management of water and stormwater, recycling and industry location assessment. A total of 14 papers appeared in this section; available online: http://sciforum.net/conf/wsf2/sections/e/.

The 17 submissions to Section F., Sustainable Development Policy and Practice, were concerned on the one hand with papers addressing theoretical issues and policy approaches for sustainability and sustainable development and, on the other hand, with case studies of specific issues such as natural disasters and rural development. Approaches covered in this section ranged from national policies based on political initiatives to the need for community involvement in policy development; available online: http://sciforum.net/conf/wsf2/sections/f/. 
Sustainable Entrepreneurship and Sustainability Innovation in Section G, was a section included for the first time in the Forum, and mainly dealt with different innovation issues within the corporate environment. However, issues related to responsible innovation, ecological efficiency and rural development were also represented; available online: http://sciforum.net/conf/wsf2/sections/g/.

In Section H., Remote Sensing for Sustainable Management of Land and Biodiversity, Sustainable Agriculture remote sensing methods were discussed. Furthermore a study about biodiversity management in Iran was included; available online: http://sciforum.net/conf/wsf2/sections/h/.

Various topics were collected in the last section, Related Topics. These included new topics such as the discussion of healthy light sources or the link between the novel term geoethics and sustainability; available online: http://sciforum.net/conf/wsf2/sections/i/.

\subsection{Further Material}

Beyond the submissions to the sections, a recorded keynote presentation by Dr. Marc A. Rosen, the Chairman of WSF and Editor-in-Chief of the journal Sustainability, was posted, and several videos that support the submissions were made available at the Forum web site.

In order to facilitate discussions among the participants of the Forum, a mailing list was established. A lively discussion surrounding the definition of the term "sustainability" itself developed via this channel. The participants employed different definitions in their papers and used the opportunity to exchange ideas and thoughts. This discussion provides an interesting insight into the debate surrounding sustainability and includes perspectives from people all over the world. It can be viewed at http://lists.mdpi.org/pipermail/wsf-2012/.

\section{Conclusions}

The 2nd World Sustainability Forum successfully permitted participants to examine, explore and critically engage with issues and advances in sustainability and related areas. By facilitating publications and debates on theoretical and practical investigations, the 2nd WSF allowed participants to "make a difference".

For the 3rd World Sustainability Forum, which takes place from 1-30 November 2013, further discussions are strongly encouraged. The Forum continues to improve and invites international scholars from different disciplines to engage in productive and interesting debates, and to report advances in all areas of sustainability.

\section{Conflict of Interest}

The authors declare no conflict of interest.

(C) 2013 by the authors; licensee MDPI, Basel, Switzerland. This article is an open access article distributed under the terms and conditions of the Creative Commons Attribution license (http://creativecommons.org/licenses/by/3.0/). 